\title{
Treatment of Severe Imipramine Poisoning
}

\author{
J. A. YOUNG and W. H. GALLOWAY \\ From The United Sheffield Hospitals and Department of Child Health, University of Aberdeen
}

Young, J. A., and Galloway, W. H. (1971). Archives of Disease in Childhood, 46, 353. Treatment of severe imipramine poisoning. Two cases are described which illustrate the successful use of diazepam and lignocaine in the management of severe poisoning by the tricyclic antidepressant group of drugs. A routine for the management of such cases is set out.

The clinical effects and treatment of imipramine and amitriptyline poisoning have been reviewed by Giles (1963) and Steel, O'Duffy, and Brown (1967). The majority of cases are mild and recover spontaneously. The severe case is characterized by coma, convulsions, and cardiac arrhythmias. There is the added risk of respiratory depression and hypotension. Poisoning is severe if the dose of the drug ingested exceeds $20 \mathrm{mg} / \mathrm{kg}$ (Steel et al., 1967).

Cairncross and Gershon (1962) have shown that the tachycardia that follows administration of these drugs in low dosage is due to vagal block. Larger doses have a direct action on the myocardium to cause AV block, extrasystoles, ventricular tachycardia, widening of the QRS complex, ST depression, and abnormal $T$ waves. They also noted that an increase in the load on the heart potentiated this toxic effect.

ECG changes have been described by Barnes, Kong, and Wu (1968) and Freeman et al. (1969).

\section{Case Reports}

Case 1. A $2 \frac{1}{2}$-year-old boy weighing $14 \mathrm{~kg}$ was admitted 11 hours after swallowing between 30 and 50 tablets $25 \mathrm{mg}$ of imipramine. He was drowsy most of the time after ingestion and admission was precipitated because of a fit and vomiting. He was limp, comatose with fixed pupils but responded to painful stimuli. There was no airway obstruction, his blood pressure was $90 / 66 \mathrm{mmHg}$ but no heart sounds could be heard.

External cardiac massage restored heart action. Paraldehyde $2 \mathrm{ml}$ was given intramuscularly because of convulsions. Intravenous infusion of $0 \cdot 18 \%$ saline and $4.3 \%$ dextrose was started. Child connected to cardiorater and defibrillator. ECG showed ventricular tachycardia. Lignocaine given as a loading dose and continuously via drip $(185 \mathrm{mg}$ in $8 \mathrm{hr}$ ). This restored idioventricular rhythm at 140 beats/min.

Received 28 September 1970.
Two hours after admission tracheal intubation was carried out and the child was placed in an oxygenenriched atmosphere. Gastric lavage and bladder catheterization were done. Further episodes of convulsions and ventricular tachycardia occurred and were controlled by lignocaine (70 $\mathrm{mg}$ over 5 hours) and by paraldehyde.

Fourteen hours after admission he became limp and comatose. Cardiac impulse was not recordable. Defibrillation after failure of external massage restored the heart action. Tracheal suction caused further ventricular tachycardia when cardiac impulse again failed and he became apnoeic. External massage restarted the heart. He was reintubated and connected to a ventilator. 19 hours after admission he tended to 'fight' the ventilator and was making spontaneous movements. Repeated electrolyte and blood gas estimations were normal. 22 hours after admission he was taken off the ventilator and intravenous drip was discontinued 7 hours later. Convulsions were controlled by promazine and diazepam.

On the second day he became more conscious and could swallow. Heart action remained normal. On the third day he was able to hold a cup and drinkthere were occasional jerky movements when disturbed but no true convulsions. No further sedation was needed. ECG showed 1st degree AV block, but was otherwise normal.

The following day he was irritable but conscious and alert. He continued to improve and when discharged 13 days after admission was normal.

Case 2. A 20-month-old boy was admitted 40 minutes after swallowing about 50 tablets $25 \mathrm{mg}$ of imipramine (about $100 \mathrm{mg} / \mathrm{kg}$ ). He was unconscious, cyanosed, and convulsing, his heart rate varied between 120 and 160 per min and his BP $70 \mathrm{mmHg}$ systolic. No airway obstruction or respiratory difficulty was present.

Phenobarbitone $60 \mathrm{mg}$ and paraldehyde $2 \mathrm{ml}$ were given intramuscularly, and as convulsions were not controlled, neostigmine was administered. Endotracheal intubation and gastric lavage were carried out. 
Convulsions were not controlled until a total of $6 \mathrm{mg}$ diazepam had been given intravenously. ECG examination showed ventricular rhythm (with wide complexes and ST shift). An intravenous infusion of $0.18 \%$ saline with $4 \cdot 3 \%$ dextrose was started. Lignocaine was added to this infusion $(60 \mathrm{mg}$ over the first 20 minutes) then at a rate of $40 \mathrm{mg}$ in $40 \mathrm{ml}$ infusion fluid per hour, i.e. $0.66 \mathrm{mg}$ lignocaine per minute. This caused a reversion to sinus rhythm which was maintained. He was transferred to the intensive care unit and his cardiac action was monitored. Assisted respiration was not required but the inspired air was humidified.

Adequate sedation was achieved by administering diazepam $1.5 \mathrm{mg}$ intravenously every 3 hours. 9 hours after admission the intravenous cannula snapped and he was without lignocaine for about 30 minutes, during which period he developed bursts of ventricular tachycardia requiring $50 \mathrm{mg}$ lignocaine intravenously for control. Interference such as sucking out the endotracheal tube caused ventricular tachycardia. This could be controlled and, in fact, prevented by increasing the rate of infusion to cover such procedures. After treatment for 24 hours the lignocaine concentration was reduced to $10 \mathrm{mg}$ every 12 hours, sinus rhythm being maintained. 24 hours later, the sedation was gradually withdrawn over the next 2 days with no episodes of uncontrolled behaviour. Throughout, respiration was adequate, electrolyte estimations, blood pressure, and urine flow were normal.

After a few days of convalescence, he was discharged and when seen for review was normal.

\section{Discussion}

Removal of drug from body. The tricyclic antidepressants and their active metabolites are firmly protein bound, and though forced diuresis (Prout, Young, and Goddard, 1965) and haemodialysis (Bland and McQuaid, 1966) have been advocated, others have shown that these methods are of no benefit and may well be dangerous. Gastric lavage is the only method of removing the drug. This must be performed with the usual precautions, but in view of the bursts of ventricular tachycardia associated with endotracheal intubation in both cases and the cardiac arrest during endotracheal intubation in the case described by Pearson, Jones, and Gabbe (1969), it may be wise to postpone intubation and gastric lavage until any severe ventricular arrhythmia has been controlled (Sunshine and Yaffe, 1963; Steel et al., 1967).

Choice of anticonvulsant. Barbiturates have been used frequently and are recommended in this situation (Rasmussen, 1965). The respiratory depressant action of this group of drugs, an action that is potentiated by amitriptyline, is undesirable, particularly since repeated doses are necessary to control the persistent drug convulsions. If barbiturates are used, one must be prepared to ventilate the patient. Paraldehyde does not have the same degree of disadvantage in this respect, but repeated injections of this drug may cause local problems. Diazepam is widely regarded as a first choice anticonvulsant and is relatively free from respiratory depressant effects. Respiratory depression and hypotension have occurred in adults in status epilepticus given diazepam after large doses of barbiturates and paraldehyde (Bell, 1969), but this danger does not seem to exist when diazepam is the sole anticonvulsant used.

Choice of antiarrhythmic agent. It is logical to counteract the anticholinergic effect with pyridostigmine as suggested by Rasmussen (1965). It may, however, be more effective in the management of supraventricular arrhythmias. Propranolol is an effective antiarrhythmic agent, but its negative isotopic effect is a major disadvantage. Lignocaine is effective against ventricular arrhythmias. In the usual dose range it does not cause hypotension or depression of myocardial contractile force. It acts by causing an increase of the stimulation threshold of the ventricles during diastole (Harrison, Sprouse, and Morrow, 1963). It is widely used in coronary care units (Lown et al., 1967). An anticonvulsant action has been shown, and this is an added advantage in this situation (Taverner and Bain, 1958). Its main advantage is its relatively short duration of action which allows accurate titration of the dose against the cardiac action shown in the oscilloscope.

The first patient was treated empirically as no scheme was available. The experience gained by treating the two patients reported allowed the following scheme to be devised.

Scheme for the management of severe poisoning by the tricyclic antidepressants $(>20 \mathrm{mg} / \mathrm{kg}$ body weight).

(1) Give oxygen by face mask.

(2) Control convulsions with diazepam $0.2 \mathrm{mg} / \mathrm{kg}$.

(3) Establish cardiac rhythm by ECG. If ventricular arrhythmia, control this with lignocaine intravenously $1 \mathrm{mg} / \mathrm{kg}$. Repeat as necessary.

(4) Establish a reliable intravenous infusion of $0.18 \%$ saline and $4.3 \%$ dextrose to run at maintenance rate. Add lignocaine to give $0.5-1 \mathrm{mg}$ per minute.

(5) Endotracheal intubation.

(6) Gastric lavage.

(7) Transfer to an intensive care situation.

(8) Adjust concentration of lignocaine infusion to control cardiac action. Give bolus of $1 \mathrm{mg} / \mathrm{kg}$ as required. Gradually withdraw lignocaine over 48 to 72 hours.

(9) Maintain sedation with diazepam $0.1 \mathrm{mg} / \mathrm{kg}$ 4-hourly, adjust dose as required. 
(10) Monitor and support respiration, BP, renal function.

(11) Increase lignocaine infusion to cover such procedures as tracheal toilet.

Neostigmine $1 \mathrm{mg}$ may be of value in the case of supraventricular tachycardia.

Haemodialysis and forced diuresis and hypertensive agents are contraindicated.

The above doses are reasonable starting points, but may need to be increased.

We thank Dr. J. A. Black for permission to publish Case 2.

\section{REFERENCES}

Barnes, R. J., Kong, S. M., and Wu, R. W. Y. (1968). Electrocardiographic changes in amitriptyline poisoning. British Medical fournal, 3, 222.

Bell, D. S. (1969). Dangers of treatment of status epilepticus with diazepam. British Medical fournal, 1, 159.

Bland, D. C., and McQuaid, A. (1966). Successful treatment by haemodialysis of massive overdose of imipramine and sodium amytal. Clinical Trials fournal, 3, 425.

Cairncross, K. D., and Gershon, S. (1962). A pharmacological basis for the cardiovascular complications of imipramine medication. Medical fournal of Australia, 2, 372.
Freeman, J. W., Mundy, G. R., Beattie, R. R., and Ryan, C. (1969). Cardiac abnormalities in poisoning with tricyclic antidepressants. British Medical fournal, 2, 610.

Giles, H. McC. (1963). Imipramine poisoning in childhood. British Medical fournal, 2, 844.

Harrison, D. C., Sprouse, J. H., and Morrow, A. G. (1963). The antiarrhythmic properties of lidocaine and procaine amide. Circulation, 28, 486.

Lown, B., Fakhro, A. M., Hood, W. B., Jr., and Thorn, G. W. (1967). The coronary care unit: new perspectives and directions. fournal of the American Medical Association, 199, 188.

Pearson, J. D., Jones, E. S., and Gabbe, D. M. (1969). Cardiac arrest and arrhythmias due to self-poisoning with imipramine. Anaesthesia, 24, 69.

Prout, B. J., Young, J., and Goddard, P. (1965). Imipramine poisoning in childhood and suggested treatment. British Medical Fournal, $1,972$.

Rasmussen, J. (1965). Amitriptyline and imipramine poisoning. Lancet, 2, 850.

Steel, C. M., O'Duffy, J., and Brown, S. S. (1967). Clinical effects and treatment of imipramine and amitriptyline poisoning in children. British Medical fournal, 3, 663 .

Sunshine, P., and Yaffe, S. J. (1963). Amitriptyline poisoning. American fournal of Diseases of Children, 106, 501.

Taverner, D., and Bain, W. A. (1958). Intravenous lignocaine as an anticonvulsant in status epilepticus and serial epilepsy. Lancet, 2, 1145.

Correspondence to Dr. W. H. Galloway, Royal Aberdeen Children's Hospital, Cornhill Road, Aberdeen. 